\title{
Lobby: instrumento democrático de representação de interesses?
}

\author{
Lobby: a democratic instrument of \\ representation of interests?
}

\author{
Lobby: iinstrumento democrático de \\ representación de intereses?
}

Wagner Pralon Mancuso

- Doutor em Ciência Política pela Faculdade de Filosofia, Letras e Ciências Humanas da Universidade de São Paulo (FFLCH-USP)

- Docente do curso de graduação em Gestão de Políticas Públicas da Escola de Artes e Ciências Humanas da Universidade de São Paulo (EACH/USP)

- Docente dos Programas de Pós-Graduação em Ciência Política e em Relações Internacionais da Universidade de São Paulo (USP).

- Autor do livro O lobby da indústria no Congresso Nacional: empresariado e política no Brasil contemporâneo

- pralon@usp.br

\section{Andréa Cristina Oliveira Gozetto}

- Doutora em Ciências Sociais pelo Instituto de Filosofia e Ciências Humanas da Universidade Estadual de Campinas (Unicamp)

- Docente do Programa de Pós-Graduação Lato Sensu em Direito e docente e pesquisadora do curso de graduação em Direito da Universidade Nove de Julho (Uninove)

- Administradora do blog www.blog.lobbying.com.br

• acjoliveira@gmail.com 
Esse artigo analisa o potencial do lobby como instrumento democrático de representação de interesses. Por um lado, o artigo relaciona contribuições positivas que o lobby pode trazer para o processo democrático. Por outro lado, aponta problemas que o lobby pode ocasionar, à luz do valor democrático da igualdade política. O texto também discute a questão da regulamentação do lobby, focalizando os objetivos dessa medida, os fatores que dificultam sua adoção no Brasil e o conjunto de iniciativas que, juntamente com a regulamentação da atividade, podem contribuir para tornar o lobby um efetivo instrumento democrático de representação de interesses.

PALAVRAS-CHAVE: LOBBY • REPRESENTAÇÃO DE INTERESSES • DEMOCRACIA • PROCESSO DECISÓRIO • REGULAMENTAÇÃO DO LOBBY

\section{Abstract}

This article analyzes the potential of lobbying as a democratic instrument of representation of interest. On the one hand, the article highlights the positive contributions of lobbying activities to the democratic process. On the other hand, the article identifies some problems that lobbying activities can generate, in the light of the democratic value of political equality. The text also discusses the question of lobbying regulation, focusing on (i) the purposes of this measure, (ii) the factors which hinder its adoption in Brazil, and (iii) the set of initiatives that - together with lobbying regulation - could contribute to making lobbying become an effective democratic instrument of representation of interests.

KEYWORDS: LOBBYING • INTEREST REPRESENTATION • DEMOCRACY • DECISION-MAKING PROCESS • LOBBYING REGULATION

\section{Resumen}

Este artículo examina el potencial del lobby como instrumento de representación democrática de intereses. Por una parte, relaciona las contribuciones positivas que el lobby puede aportar al proceso democrático. Por otra, señala los problemas que el lobby puede producir a la luz del valor democrático de la igualdad política. El artículo también debate la cuestión de la regulación del lobby, centrándose en los objetivos de tal medida, en los factores que dificultan su adopción en Brasil y en el conjunto de iniciativas que, junto con la regulación de la actividad, pueden ayudar a hacer del lobby un instrumento democrático de la representación de intereses.

PALABRAS CLAVE: LOBBY • REPRESENTACIÓN DE INTERESES • DEMOCRACIA • PROCESOS DE TOMA DE DECISIÓN • REGULACIÓN DEL LOBBY 
obby já é uma palavra definitivamente incorporada ao vocabulário dos brasiLleiros. Cotidianamente, a palavra é usada de forma bastante abrangente, para designar a defesa de interesses diante de qualquer indivíduo que pode tomar uma decisão. Nesse sentido informal, fala-se de lobby até mesmo quando a mídia pressiona o técnico da seleção brasileira de futebol para convocar um jogador em evidência, ou quando um grupo de alunos pressiona seu professor para "aliviar" na hora de atribuir notas às provas. Já na literatura acadêmica, o conceito de lobby possui um significado mais restrito, referindo-se à defesa de interesses diante de membros do poder público que podem tomar decisões políticas.

Trata-se de uma palavra que veio da língua inglesa e, etimologicamente, designa o salão de entrada de edifícios. Mas o substantivo tornou-se um verbo, e a palavra saltou do léxico da arquitetura para o jargão da política, para referir-se à atuação de representantes de interesses (os "lobistas") que, para apresentar seus pleitos, esperavam a passagem de tomadores de decisões políticas pelo salão de entrada dos edifícios onde eles se hospedavam ou trabalhavam.

A prática do lobby político se fortaleceu no Brasil com a redemocratização, a partir de meados da década de 1980 (Diniz; Boschi, 2000), pois o processo de tomada de decisões públicas tornou-se mais acessível com a abertura política. Mesmo assim, o lobby ainda é um assunto pouco estudado no país, pois a atividade não está regulamentada e é envolvida por certo estigma de marginalidade.

Dessa forma, é pequeno o número de trabalhos mais gerais, que oferecem uma visão panorâmica sobre a atividade do lobby no Brasil (Aragão, 1994 e 2000; Vianna 1994; Oliveira, 2004; Farhat, 2007). E também é reduzido o número de trabalhos mais focalizados, que se aprofundam na análise do lobby de determinados segmentos sociais (Mancuso, 2007) ou em torno de processos decisórios específicos (Taglialegna 2005, Ramos, 2005).

Este artigo discute o potencial do lobby como instrumento democrático de representação de interesses. Para alcançar esse objetivo, iniciamos o texto advogando uma concepção não-maniqueísta do lobby, argumentando que ele pode ocorrer tanto de forma ilícita quanto de forma lícita. Em segundo lugar, apresentamos os dispositivos constitucionais que, em nosso entendimento, respaldam o lobby lícito como instrumento à disposição dos segmentos sociais para a defesa de seus interesses. Em terceiro lugar, relacionamos as contribuições positivas que o lobby lícito pode trazer para o processo democrático - seja para os tomadores de decisão, para os interesses organizados, para a opinião pública e para o sistema político como um todo. Em quarto lugar, focalizamos dois problemas que até mesmo o lobby lícito pode ocasionar, à luz do valor democrático da igualdade política: o desequilíbrio entre os lobbies atuantes e a concessão de privilégios injustificáveis a interesses determinados. Em quinto lugar, discutimos o potencial da regulamentação do lobby como medida adequada para combater o lobby ilícito, potencializar as contribuições positivas do lobby lícito e contrabalançar o desequilíbrio que pode resultar 
no favorecimento injustificável de interesses especiais. Por fim, identificamos fatores que têm obstado a regulamentação do lobby no Brasil e apontamos medidas que podem, juntamente com a regulamentação, integrar uma estratégia ampla e multifacetada para tornar o lobby um efetivo instrumento democrático de representação de interesses.

\section{LOBBY: INSTRUMENTO DEMOCRÁTICO DE REPRESENTAÇÃO DE INTERESSES?}

Neste trabalho, adotamos a concepção acadêmica da palavra lobby, definindo-a como atividade de defesa de interesses afetados por decisões públicas. Literalmente, lobby é uma palavra neutra, pois a definição do conceito não estabelece a priori que a defesa de interesses seja feita de modo lícito ou ilícito. Todavia, o lobby muitas vezes é associado exclusivamente à defesa ilícita de interesses. Conforme essa visão, ele sempre toma a forma de práticas proibidas pelas leis vigentes.

Os escândalos políticos denunciados diariamente pela mídia mostram que a interação de lobistas com membros do poder público pode, de fato, resultar em crimes contra a administração pública - tais como corrupção ativa e passiva, tráfico de influência, fraude de concorrências, entre outros.

Ao denunciar escândalos políticos, a mídia constitui-se em um importante instrumento de controle, que fomenta o combate à corrupção no país. Contudo, ao praticamente identificar o lobby com práticas ilícitas, a mídia contribuiu para o predomínio, entre nós, de uma visão negativa da atividade. Nas denúncias da mídia, os lobistas muitas vezes são apresentados como indivíduos que buscam vantagens indevidas diante do poder público e para isso recorrem a ameaças ou à oferta de recompensas ilegais. A figura arquetípica do lobista passou a ser a do indivíduo que atua de forma obscura e dissimulada, procurando acesso privilegiado aos tomadores de decisão, sempre disposto a entrar em negociatas com agentes públicos capazes de ajudá-lo na obtenção de seus objetivos.

Os próprios lobistas não têm ignorado a percepção social predominantemente negativa de sua atividade. Em função do forte estigma negativo que envolve a prática do lobby, muitos deles optam por identificar-se como profissionais de relações governamentais; representação institucional; consultoria, análise e assessoria política; advocacia corporativa, entre outras denominações.

Quando feito de forma ilícita, o lobby acarreta uma série de problemas relevantes. Cada um a seu modo, tanto a mídia, quanto a sociedade civil organizada e órgãos públicos, tais como o Ministério Público, o Poder Judiciário, a Polícia Federal, as Corregedorias e os Tribunais de Contas, dentre outros - têm um papel importante para coibir o lobby ilícito, garantir a punição dos culpados e assim salvaguardar o interesse público. 
Entretanto, fiéis ao significado literal valorativamente neutro da palavra lobby, adotamos neste artigo uma concepção não-maniqueísta da atividade. Entendemos que o lobby não é lícito ou ilícito por natureza ou definição e que uma visão maniqueísta da atividade atrapalha o aprofundamento da análise sobre sua prática no Brasil. Em outras palavras, entendemos que, assim como seria inadequado ignorar a relação existente entre lobby e práticas ilegais, associá-lo exclusivamente à defesa ilícita de interesses significaria desprezar as contribuições positivas que pode proporcionar.

Direitos expressos no artigo $5^{\circ}$ de nossa Constituição Federal asseguram ao lobby lícito compatibilidade com o ordenamento jurídico de um estado democrático de direito, alicerçado no pluralismo político. Entre eles podemos citar os direitos: (i) à liberdade de manifestação de pensamento (inciso IV); (ii) à expressão da atividade intelectual, artística, científica e de comunicação (inciso IX); (iii) à liberdade de reunião (inciso XVI); à liberdade de associação para fins lícitos (inciso XVII); (iv) ao acesso à informação pública de interesse particular, coletivo ou geral (inciso XXXIII); e (v) de petição aos poderes públicos, em defesa de direitos ou contra ilegalidade ou abuso de poder (inciso XXXIV, alínea a).

Dessa forma, é possível afirmar que o lobby lícito integra o conjunto de instrumentos à disposição dos segmentos sociais para a promoção de seus interesses. Além dele, a constituição proporciona à sociedade outros meios de participação nas decisões políticas, tais como: (i) as eleições regulares para o preenchimento de cargos públicos dos poderes legislativo e executivo; (ii) o voto em plebiscitos e referendos; e (iii) a iniciativa popular de proposições legislativas. Deve ser ressaltada, ainda, a possibilidade de participação dos interesses organizados em outros mecanismos institucionais, tais como audiências públicas, consultas públicas, conselhos gestores, dentre outros.

O lobby lícito pode constituir-se em instrumento democrático de representação de interesses, ao trazer contribuições positivas para os tomadores de decisão, a opinião pública, os interesses representados e o sistema político como um todo.

Os tomadores de decisão são confrontados com uma grande variedade de questões sobre as quais precisam deliberar, mas em relação às quais possuem informações apenas incompletas. Muitas vezes as questões da agenda decisória são complexas, envolvendo múltiplos interesses legítimos, que precisam ser levados em conta simultaneamente em um processo decisório democrático. Os lobbies colaboram com a difícil tarefa dos tomadores de decisão ao proporcionar-lhes informações sobre os itens que figuram na agenda. Em um contexto no qual são respeitados os direitos políticos mencionados anteriormente, os diferentes lados de uma mesma questão podem ter lobistas ativos, operando em controle mútuo. O confronto entre lobistas de interesses opostos pode ajudar o tomador de decisão a ter uma visão mais completa da questão em jogo, bem como a evitar decisões apressadas e imperfeitas. Em outras palavras, 
os lobbies podem colaborar para o aprimoramento das decisões tomadas, ajudando os tomadores de decisão a forjar soluções satisfatórias para as diversas partes legítimas envolvidas.

O lobby lícito também pode concorrer para o refinamento da opinião públi$\mathrm{ca}$, ao fornecer informações e fomentar o debate sobre questões que figuram na agenda decisória do poder público. Essa contribuição pode gerar uma visão mais profunda e abrangente sobre os problemas públicos - problemas sobre os quais a opinião pública pode ser chamada a se pronunciar diretamente, seja em consultas públicas, eleições, plebiscitos, referendos ou outros mecanismos de participação.

O lobby lícito pode trazer várias contribuições positivas para os interesses representados. Em primeiro lugar, o lobby pode aproximar o resultado decisório das preferências dos interesses organizados. Em segundo lugar, o lobby lícito pode proporcionar aos interesses organizados a satisfação íntima de "fazer parte do jogo", mediante a defesa pública e aberta dos próprios pontos de vista, com o intuito de enriquecer o debate sobre as questões públicas. Em terceiro lugar, pela via do lobby lícito, a participação em processos decisórios abertos pode resultar em subprodutos valiosos para quem participa. É isso que ensinam os expoentes da teoria da democracia participativa, a exemplo de Carole Pateman (1992). O primeiro desses subprodutos é a educação política: (i) que leva o participante, ao tratar de questões coletivas, a considerar não apenas seus interesses particulares, mas também os interesses públicos; (ii) que desenvolve em quem participa a capacidade de defender suas posições de forma clara e bem fundamentada; (iii) e que acostuma o participante a aceitar as decisões bem instruídas da maioria, familiarizando-o com os procedimentos democráticos. Além da educação política, a participação gera outros subprodutos importantes, pois integra o participante à própria comunidade e o leva a aceitar as decisões coletivas mais facilmente, pois sente que seus pontos de vista não foram ignorados no processo deliberativo. Em síntese, um contexto decisório aberto e participativo favorece a formação de lobbies integrados à comunidade política, que atuem de forma politicamente educada e que aceitem os resultados do processo democrático.

Por fim, o lobby lícito pode beneficiar o sistema político como um todo. Primeiramente, o lobby em defesa de "grandes causas" (por exemplo, o desenvolvimento sustentável e o combate à corrupção na política) contribui diretamente para a satisfação do interesse público. Além disso, o lobby lícito fortalece o sentimento de pertença dos interesses organizados à comunidade política, colaborando para legitimar a própria comunidade e seu poder público. Ao criar um canal de comunicação entre os interesses organizados e o poder público, o lobby lícito contribui para a legitimação do sistema político, pois assegura que as demandas de relevantes interesses sociais serão efetivamente consideradas durante os processos decisórios - na ausência desse canal, a legitimidade do sistema político poderia vir a ser contestada. 
Se é verdade que o lobby lícito pode acarretar diversas contribuições positivas, também é verdade que pode dar margem a problemas relevantes, à luz do princípio democrático da igualdade política. Destacaremos, aqui, dois problemas interligados: o desequilíbrio entre os lobbies atuantes e a concessão de privilégios injustificáveis a interesses determinados.

É sabido que os diferentes segmentos sociais não são igualmente capazes de se organizar ou de arregimentar recursos para formar lobbies em defesa de seus interesses. Quanto à capacidade de organização, a literatura indica que grupos pouco numerosos (por exemplo, os empresários de setores econômicos oligopolizados) têm maior facilidade que grupos grandes (por exemplo, os consumidores de um mercado competitivo ou os contribuintes) para resolver problemas de ação coletiva e constituir lobbies em busca de benefícios para seus membros (Olson, 1999).

Também é variada a capacidade dos diferentes segmentos sociais para arregimentar recursos e sustentar lobbies ativos. Dentre os recursos políticos, o dinheiro é um dos mais importantes e fungíveis - ou seja, é um dos que pode ser utilizado de formas mais diferentes para o alcance do mesmo fim: a influência política. De fato, o dinheiro pode viabilizar numerosas atividades, tais como contribuições para campanhas eleitorais, a contratação de lobistas talentosos e bem preparados, o patrocínio de sólidos estudos técnicos, a realização de campanhas publicitárias persuasivas, dentre outras. Sendo assim, os segmentos sociais mais bem financiados têm melhores condições de formar lobbies influentes em defesa de seus interesses.

Operando em conjunto, as duas tendências apontadas acima podem instaurar um desequilíbrio em favor dos lobbies que defendem interesses "especiais", ou seja, interesses de segmentos sociais estreitos, extremamente bem organizados e fartamente financiados.

Esse desequilíbrio poderia ser contrabalançado de duas maneiras: de um lado, por meio da atuação de empreendedores políticos dispostos a assumir, por conta própria, a tarefa de organizar a defesa dos interesses com dificuldade de ação coletiva (por exemplo, o Idec - Instituto Brasileiro de Defesa do Consumidor). De outro lado, por meio da atuação do próprio poder público, com vistas a: (i) patrocinar a organização de segmentos sociais desmobilizados; (ii) facilitar o acesso de segmentos marginalizados às instâncias decisórias; ou (iii) decidir considerar os interesses de todas as partes envolvidas em um processo decisório, mesmo quando as partes estejam desigualmente organizadas e mobilizadas. Entretanto, não há como garantir que essas fontes de reequilíbrio estejam sempre operantes.

Esse desequilíbrio pode criar situações problemáticas, à luz do valor democrático da igualdade política. Ele pode levar o poder público a conceder privilégios indefensáveis em favor de interesses especiais apoiados por lobbies 
fortes - mesmo que esses privilégios sejam alcançados pela devida via legal. É o que ocorre, por exemplo, quando a maioria da sociedade arca com uma carga tributária elevadíssima, enquanto setores empresariais específicos são contemplados por leis que lhes concedem benefícios tributários injustificáveis ${ }^{1}$. Aprovados de forma pouco transparente, e sem evidências conclusivas em favor de sua eficiência, eficácia e efetividade, tais benefícios particulares são concedidos às expensas do restante da sociedade, a qual deixa de receber serviços que poderiam ser financiados pela receita renunciada e/ou tem a carga tributária ainda mais aumentada, para compensar a perda de receitas (Mancuso; Gonçalves; Mencarini, 2010).

Em síntese, quando a força dos lobbies é muito desequilibrada e os lobbies mais fortes arrancam privilégios injustificáveis do poder público, as desigualdades já existentes podem ser ainda mais reforçadas e o interesse público é colocado sob grave ameaça.

Diante do exposto, o desafio fundamental é construir instituições que, simultaneamente, combatam o lobby ilícito, potencializem as contribuições positivas do lobby lícito, e contrabalancem o desequilíbrio que pode resultar no favorecimento injustificável de interesses especiais.

\section{REGULAMENTAÇÃO DO LOBBY: ALCANCE E LIMITES}

A regulamentação do lobby é um tema continuamente retomado no Brasil, quando estouram escândalos políticos ligados à prática do lobby ilícito. Até o momento, no entanto, o interesse pela regulamentação do lobby sempre tem refluído, à medida que os escândalos perdem destaque no noticiário. É pertinente questionar se a regulamentação do lobby contribuiria para enfrentar o desafio formulado no parágrafo anterior.

Duas propostas de regulamentação do lobby tramitam atualmente no Congresso Nacional. A primeira (PLS n ${ }^{\circ} 203 / 1989$ ) foi apresentada por Marco Maciel há 22 anos, quando era senador de Pernambuco pelo Partido da Frente Liberal (hoje Democratas). Aprovada rapidamente pelo Senado, a proposição está engavetada na Câmara dos Deputados há mais de duas décadas (PL n ${ }^{\circ}$ $6.132 / 1990)$. A segunda proposta é mais recente, apresentada há quatro anos

1 Em nossa opinião, nem todo benefício tributário é injustificável. Experiências exitosas de política industrial mostram que políticas de apoio a setores econômicos particularmente promissores, quando bem formuladas, podem acarretar vantagens para seus beneficiários mais diretos (os insiders, ou seja, os empresários e seus fornecedores, empregados e clientes) e, ao mesmo tempo, gerar externalidades positivas para os outsiders, ou seja, o restante da sociedade (Evans, 2004). Também há políticas públicas de apoio a segmentos sociais específicos que: (i) corrigem injustiças históricas (por exemplo, políticas que beneficiam comunidades indígenas ou quilombolas); (ii) promovem a igualdade de oportunidades (por exemplo, políticas que beneficiam portadores de necessidades especiais); ou (iii) combatem a discriminação (por exemplo, políticas que estabelecem a igualdade de gênero ou punem a homofobia). 
por Carlos Zarattini (PL n $\left.{ }^{\circ} 1.202 / 2007\right)$, deputado federal paulista pelo Partido dos Trabalhadores (PT). A proposta de Zarattini também não avançou.

Com algumas diferenças entre si, as duas propostas tratam de cinco pontos principais: (i) determinam o credenciamento dos lobistas; (ii) obrigam os lobistas a declarar suas matérias de interesse, os gastos e atividades realizados para defender interesses, bem como a identidade de quem os contratou; (iii) determinam a divulgação pública dessas declarações; (iv) estabelecem punições para os lobistas e os agentes públicos que desrespeitarem as regras; e (v) criam medidas para garantir o contraditório durante processos públicos de tomada de decisão, com vistas ao equilíbrio de poder entre os interesses organizados.

É possível afirmar, portanto, que as propostas de regulamentação do lobby no Brasil têm dois objetivos centrais: em primeiro lugar, dar transparência à defesa de interesses diante do poder público - objetivo promovido pelos pontos (i) a (iv), acima; e, em segundo lugar, equilibrar o jogo de interesses em torno dos processos decisórios - objetivo buscado pelo ponto (v).

Quanto ao objetivo da transparência, a ideia é promovê-lo por meio da divulgação pública da atividade dos lobistas referente às questões que interessam a quem contrata seus serviços. Espera-se que a publicização transparente do lobby gere diversos subprodutos valiosos: (i) combata acordos secretos e ilícitos entre lobistas e agentes públicos; (ii) incentive os interesses organizados a apresentar melhores argumentos em defesa de seus pleitos; (iii) facilite o trabalho realizado pela mídia e por organizações sociais de defesa do interesse público, para informar a sociedade sobre a atuação dos interesses organizados em torno de questões que figuram na pauta decisória do poder público; (iv) desperte a atenção dos cidadãos para os processos decisórios em curso, bem como para os interesses que esses processos mobilizam, capacitando-os a formar opiniões bem fundamentadas sobre as questões públicas, e seu impacto potencial em suas vidas. Essas opiniões podem orientar a participação qualificada dos cidadãos em eventos como eleições, consultas públicas e audiências públicas, entre outros; e (v) motive segmentos sociais desmobilizados a participar do jogo político, ao perceberem que interesses opostos já estão envolvidos ${ }^{2}$.

Quanto ao objetivo de equilibrar o jogo de interesses, a ideia é garanti-lo obrigando os tomadores de decisão a recepcionarem correntes de opinião diversas, sempre que forem alvos de um lobby específico, enquanto estiverem se instruindo para a deliberação. Essa determinação pode ser de grande utilidade quando a transparência do lobby não for suficiente, por si só, para mobilizar interesses antagônicos.

2 A publicização do lobby também pode gerar informações empíricas utilíssimas para trabalhos acadêmicos sobre a atividade. Ou seja, além das motivações cívicas, também há razões de autointeresse acadêmico para os autores defenderem a regulamentação do lobby no Brasil. 
Pelo exposto acima, há razões sólidas para acreditar que a regulamentação do lobby pode trazer um avanço significativo para a vida política brasileira, ajudando a combater o lobby ilícito, favorecendo as contribuições positivas do lobby lícito e contrabalançando desequilíbrios propensos a resultar em favorecimentos injustificáveis de interesses especiais. Em outras palavras, a regulamentação do lobby pode contribuir para torná-lo um efetivo instrumento democrático de representação de interesses, desde que seja acompanhada por mecanismos eficazes de fiscalização e punição de eventuais desvios.

Se a regulamentação do lobby é uma medida tão promissora, cabe então perguntar por que ainda não foi adotada. Em nossa opinião, quatro fatores têm obstado a regulamentação do lobby no Brasil. Em primeiro lugar, há certa falta de interesse por parte dos legisladores. A regulamentação provavelmente favoreceria a profissionalização da atividade. É possível interpretar a inércia dos legisladores como um meio de evitar uma disputa com os lobistas profissionais pela representação dos interesses sociais. Em segundo lugar, há certa hesitação dos próprios lobistas em levantar a bandeira da regulamentação de forma inequívoca. Por um lado, a regulamentação promete combater o espectro de marginalidade que ronda a atividade - para os profissionais da área, isso representa um benefício significativo. Por outro lado, no entanto, a regulamentação obriga os lobistas a agir de forma transparente, forçando-os a abdicar da atuação em cenários de pouca visibilidade, mais convenientes para a defesa de interesses ilegítimos. Além disso, há o temor de que a regulamentação gere não apenas mais concorrência - inchando o mercado da representação de interesses, com a chegada de novos profissionais interessados em atuar como lobistas -, mas também mais burocracia - ao determinar a frequente prestação de contas de gastos e atividades realizadas. Em terceiro lugar, a sociedade brasileira não tem atuado como agente impulsionador da regulamentação do lobby, diferentemente do que ocorreu, por exemplo, com o projeto da ficha limpa. Por fim, em quarto lugar, o poder executivo federal ainda não encampou nenhum projeto de regulamentação do lobby - e o poder executivo tem sido o responsável pela maior parte da produção legislativa no país (Figueiredo; Limongi, 1999). Tomados em conjunto, esses fatores mostram que, para ser aprovada, a regulamentação do lobby precisará enfrentar e superar resistências significativas.

A regulamentação do lobby nos parece uma medida muito importante, mas entendemos que não deva ser encarada como uma panaceia. Acreditamos que a regulamentação deva integrar uma estratégia ampla e multifacetada para tornar o lobby mais equilibrado, virtuoso e ético. Nesse sentido, ao lado da regulamentação, outras iniciativas relevantes são as seguintes: (i) fomentar uma cultura de integridade e de repúdio à corrupção no país; (ii) aperfeiçoar e aplicar os mecanismos de controle internos e externos já existentes na administração pública; (iii) assegurar a vigilância ativa da mídia, da oposição e da cidadania como um todo, sobre os processos decisórios do poder público; (iv) formalizar e incrementar a participação pública nos processos decisórios; e (v) 
incentivar a autorregulamentação da atividade pelos próprios lobistas, com a criação de um código de conduta e de um conselho de ética que assegure sua aplicação efetiva ${ }^{3}$.

\section{REFERÊNCIAS}

ARAGÃO, Murillo de. Grupos de pressão no Congresso Nacional: como a sociedade pode defender licitamente seus direitos no poder legislativo. São Paulo: Maltese, 1994.

Brasil e Argentina: abordagem comparada sobre grupos de pressão no poder legislativo papel dos grupos no legislativo. 2000. 113 f. Tese (Doutorado em Ciência Política) - Centro de Pesquisa e Pós-Graduação sobre América Latina e Caribe, Universidade de Brasília, 2000.

DINIZ, Eli; BOSCHI, Renato. Globalização, herança corporativa e a representação dos interesses empresariais: novas configurações no cenário pós-reformas. In: BOSCHI, Renato; DINIZ, Eli; SANTOS, Fabiano. Elites políticas e econômicas no Brasil contemporâneo. São Paulo: Fundação Konrad Adenauer, 2000.

EVANS, Peter. Autonomia e parceria: estados e transformação industrial. Rio de Janeiro: Editora UFRJ, 2004.

FARHAT, Saïd. Lobby. 0 que é. Como se faz: ética e transparência na representação junto a governos São Paulo: Aberje Editorial / Editora Peirópolis, 2007.

FIGUEIREDO, Argelina; LIMONGI, Fernando. Executivo e legislativo na nova ordem constitucional. Rio de Janeiro: FGV, 1999.

MANCUSO, Wagner Pralon. O lobby da indústria no Congresso Nacional: empresariado e política no Brasil contemporâneo. São Paulo: Edusp / Humanitas / Fapesp, 2007.

MANCUSO, Wagner Pralon; GONÇALVES, Maetê Pedroso; MENCARINI, Fabrizio. Colcha de retalhos: a política de concessão de benefícios tributários ao empresariado no Brasil (1988-2006). In: MANCUSO, Wagner Pralon; LEOPOLDI, M. Antonieta; IGLECIAS, Wagner (Org.). Estado, empresariado e desenvolvimento no Brasil. São Paulo: Editora de Cultura, 2010.

OLIVEIRA, Andréa C. de Jesus. Lobby e representação de interesses: lobistas e seu impacto na representação de interesses no Brasil. 2004. 296 f. Tese (Doutorado) - Uniicamp, Campinas, 2004.

OLSON, Mancur. A lógica da ação coletiva. São Paulo: Edusp, 1999.

PATEMAN, Carole. Participação e teoria democrática. São Paulo: Paz e Terra, 1992.

RAMOS, Daniela Peixoto. Comportamento parlamentar e grupos de pressão: um estudo de caso da reforma da previdência (1995-1998). Dissertação (Mestrado) - Universidade de Brasília, Instituto de Ciência Política, Brasília, 2005.

TAGLIALEGNA, G. Henrique F. Grupos de pressão e a tramitação do projeto de lei de biossegurança no Congresso Nacional. [Texto para discussão, n. 28]. Brasíliia: Consultoria Legislativa do Senado Federal, 2005.

VIANNA, Maria Lúcia T. W. Lobismo: um novo conceito para analisar a articulação de interesses no Brasil. [Texto para discussão, n. 25]. Rio de Janeiro: Centro de Estudos de Políticas Públicas, 1994.

Recebido em: 20.04.2011 / Aceito em: 20.06.2011

3 Passos nessa direção foram tomados, em 2007, com a criação da Associação Brasileira de Relações Institucionais e Governamentais (Abrig). 